\title{
LED Lighting Systems for Horticulture: Business Growth and Global Distribution
}

\author{
Ivan Paucek ${ }^{1}$, Elisa Appolloni ${ }^{1}$, Giuseppina Pennisi 1,*(D), Stefania Quaini ${ }^{2}$, \\ Giorgio Gianquinto ${ }^{1}$ (D) and Francesco Orsini ${ }^{1}$ (D) \\ 1 DISTAL-Department of Agricultural and Food Sciences and Technologies, Alma Mater \\ Studiorum-University of Bologna, 40127 Bologna, Italy; ivan.paucekpagan2@unibo.it (I.P.); \\ elisa.appolloni3@unibo.it (E.A.); giorgio.gianquinto@unibo.it (G.G.); f.orsini@unibo.it (F.O.) \\ 2 FEEM-Foundation Eni Enrico Mattei, 20123 Milano, Italy; stefania.quaini@feem.it \\ * Correspondence: giuseppina.pennisi@unibo.it
}

Received: 4 August 2020; Accepted: 5 September 2020; Published: 11 September 2020

\begin{abstract}
In recent years, research on light emitting diodes (LEDs) has highlighted their great potential as a lighting system for plant growth, development and metabolism control. The suitability of LED devices for plant cultivation has turned the technology into a main component in controlled or closed plant-growing environments, experiencing an extremely fast development of horticulture LED metrics. In this context, the present study aims to provide an insight into the current global horticulture LED industry and the present features and potentialities for LEDs' applications. An updated review of this industry has been integrated through a database compilation of 301 manufacturers and 1473 LED lighting systems for plant growth. The research identifies Europe (40\%) and North America (29\%) as the main regions for production. Additionally, the current LED luminaires' lifespans show 10 and $30 \%$ losses of light output after 45,000 and 60,000 working hours on average, respectively, while the vast majority of worldwide LED lighting systems present efficacy values ranging from 2 to $3 \mu \mathrm{mol} \mathrm{J}^{-1}$ $(70 \%)$. Thus, an update on the status of the horticultural LED sector, LEDs' applications and metrics, and the intense innovation are described and discussed.
\end{abstract}

Keywords: light emitting diode; LED grow light; horticultural lighting; energy use efficiency; luminaire typology; greenhouse supplemental lighting; vertical farming; indoor cultivation; sustainability

\section{Introduction}

The use of artificial light for plant growth and development purposes has been known for more than a century [1]. However, until recently, horticultural lighting systems were based on the traditional industry and therefore not specifically designed for plant growth applications [2]. Particularly, only in the last few decades lighting technologies, such as fluorescent (FL), high-pressure sodium (HPS), metal halide (MH) and incandescent (INC) lamps, have started to be implemented for plant cultivation and research [3]. Light is the most important source of energy for photosynthesis; therefore, the lighting environment surrounding plant canopy can differently influence plant growth and development [4]. The above-mentioned artificial lighting sources (e.g., FL, HPS, MH and INC lamps) can present several drawbacks, as they are not spectrally optimal for crops nor energetically efficient, furthermore releasing a large amount of radiant heat [3]. The most recent light emitting diodes (LEDs) have replaced conventional lighting technologies in many indoor and protected environments, resulting in great and rapid technological evolution in the horticultural lighting industry [5].

Horticultural LED luminaires represent solutions more environmentally friendly and economically favorable than conventional lighting while having safer management and disposal practices [3]. 
In contrast with traditional HPS lamps, which convert only $30 \%$ of the energy into usable light, with significant radiation losses in the form of heat, LED lighting sources often convert about $50 \%$ of the electricity into light, resulting in an economically and energetically better solution [6]. Additionally, due to a non-uniform distribution of solar radiation across world regions, supplemental illumination has been used at higher latitudes in greenhouse crop production, allowing improvements in terms of productivity and quality, and enabling year-round cultivation [7]. In this sense, a comparative study with supplemental light from traditional overhead HPS lighting vs. red and blue LEDs reported that greenhouse tomato growers can get the same yield by using LEDs while consuming only $25 \%$ of the energy used for traditional lights [8]. Moreover, greenhouse or indoor cultivation relying on lighting is expected to play an important role in fulfilling the increasing food demand [9]. Renewable energy sources (e.g., wind and solar energy) can also contribute to covering LED energy consumption, therefore improving the economic and environmental sustainability of their application [10].

LEDs are solid-state semiconductor diodes with the capacity to release energy in the form of photons after the application of a proper amount of voltage [11]. The suitability of LED lighting systems for plant-growing applications is based on their potential features (e.g., small size, durability, long lifetime and cool emitting temperature) in combination with the advantages offered by the modularity in wavelength selection and light output, and the elevated energy conversion efficiency [12]. LED application for plant growth was first studied in the 1990s [13,14], when NASA-affiliated researchers performed much of early work as preparation for the development of plant-based regenerative life-support systems for future Moon and Mars bases [15]. However, at that time, only red $(660 \mathrm{~nm})$ LEDs were available. Therefore, it could be also asserted that the actual era of LED research started with the introduction of blue LEDs to the market [5]. Today, LED lighting systems have experienced wide evolution in terms of physical shapes and designs, waveband color availability, power use reduction per unit of light output, and cost decrease per unit of light output [2]. The technical development of LEDs is said to follow Haitz's law [16], which was reformulated in 2011, stating that, every decade, the cost per unit of useful light emitted for a given waveband declines by a factor of 10 , while the amount of light generated per LED package increases by a factor of 20 [17]. However, LED lighting applications may ultimately be limited by market forces, as, for instance, some reachable light levels may also be above commercial requirements [2].

During recent years, a large number of lighting companies have entered the horticultural sector in a joint collaboration with plant producers and academics, leading to extraordinary advances in both scientific and commercial application of LED technology for plant cultivation [18]. Meanwhile, scale economy has been significantly driving cost decreases, also thanks to the increasing opportunities to regulate plant growth, development, and concentration of phytonutrients through light spectral control [2]. Thus, the efficacy values of LED lighting systems are expected to continue on a growing trend for several years, which, together with improvements in intrinsic LED features (e.g., durability, longevity, fixture design, emission spectrum, etc.), could lead to increasing applications of LED lighting systems in horticulture [18]. The rapid evolution of the sector is, for instance, represented by lighting manufacturers that release smart LED control systems together with software applications, with which artificial intelligence using sensor feedback can automatically detect plant health issues and adapt the lighting environment for greater plant production efficiency $[19,20]$.

Until recently, however, horticultural LED luminaires were not provided with any published indicator for testing, resulting in a lack of quality standards, ultimately driving confusion on industry performance metrics. Only in 2017, the American Society of Agricultural and Biological Engineers (ASABE) released the first of three expected series of standard tests for horticultural luminaires (S640 standard), establishing the quantities and units used to describe light in relation to plants [21]. Afterward, in 2018, the society focused on specifying the performance of horticultural LED luminaires with the S642 standard: "Recommended methods for measurement and testing of LED products for plant growth and development" [22]. In this context, it is very important to identify the optimal or minimal crop light requirements in protected and indoor cultivation in order to enhance the yield 
and quality of the produce [23]. A metric characterizing the luminaire, which describes how many photons a light source emits per second (expressed in $\mu \mathrm{mol} \mathrm{s}^{-1}$ ), is the Photosynthetic Photon Flux (PPF), while the Photosynthetic Photon Flux Density (PPFD) characterizes light installation depending on luminaire position in relation to the illuminated area (in $\mu \mathrm{mol} \mathrm{m}^{-2} \mathrm{~s}^{-1}$ ) [10]. Moreover, in LED lamps for plant growth, the proper electrical efficiency metric is measured in the units of micromoles of photosynthetic photons per joule of energy input $\left(\mu \mathrm{mol} \mathrm{J}^{-1}\right)$, a further and important parameter when comparing LED luminaires [24].

Due to continuous advances in LED technology and the promising opportunities for lighting regime optimization in controlled or closed plant-growth environments [25], together with the growing LED-related plant research, a continuous update on the status of the horticultural LED industry and its applications is essential [10]. The main scope of this research is to explore and characterize the global distribution of horticultural LED industry. Particularly, the study aims at identifying and categorizing LED lighting system manufacturers on a global scale and the typologies of horticultural LED lighting solutions offered in the market. Furthermore, the current potential of LED luminaires in horticulture through a compilation and evaluation of operational functions and features is addressed.

To achieve the stated objectives, the research builds on a comprehensive database compilation of LED manufacturers and luminaires from the available scientific literature, toward the identification of the main features and functionalities of LED luminaires for horticulture, opening the ground for discussion on the future trends and challenges for the sector. Within the paper, Section 2 presents the material and methods used within the review. Section 3 presents the research results and their discussion. This section is further divided in five subsections. The business growth trend is introduced together with the worldwide distribution of horticultural LED manufacturers. Moreover, LED lighting systems are grouped according to outer surface and classified by considering the largest production areas for each luminaire typology. The electricity aspects of current LED luminaires' performance are evaluated, and a detailed global analysis of LED luminaires' lifespans is included. The current efficacy of the global LED lighting industry (building on declared data) is defined. Finally, Section 4 presents the conclusion of this work, highlighting the future prospects in the LED horticultural field.

\section{Materials and Methods}

The research was implemented by the following consecutive steps: (1) definition of the research aim; (2) choice of keywords and database; (3) selection of LED grow-light manufacturing companies; (4) tabulation of the information compiled; (5) analysis and presentation of the results. Consequently, information regarding each of these stages is presented following the same sequence.

For a proper identification of the global LED grow-light manufacturing industry, different keywords were defined, while several online databases were consulted. The keywords used as the basis for manufacturer consultation were "LED horticulture", "LED grow lights" and "horticultural LED lighting", also adding the terms "manufacturers" and "companies" to perform a deeper investigation. The search was performed through online sources such as Google and LinkedIn databases. In order to perform a better search on the Google database, each country was investigated by changing the location setting and also translating the keywords into the local language. Databases of conferences, seminars, events, exhibitions or meetings databases related to the fields of LED lighting, horticulture technology, fruit and vegetable market and cannabis industry (e.g., LED Professional Symposium, GreenTech, Macfrut, HortiCann Light+Tech, etc.) were considered. Moreover, keywords were inserted in the reference journal databases for extensive research (Springerlink, Sciencedirect, Scopus and Google Scholar).

A global inventory of 301 LED lighting system manufacturers, ranging from multinational corporations to local companies, was collected. Distributors, wholesalers and retailers were excluded from the study. The global inventory of LED lighting system manufacturers was used to customize a map through the online tool "Google My Maps", from which the worldwide distribution was developed. 
Concerning the analysis of the features and operational functions of LED horticultural solutions, a database compilation based on the manufacturer global inventory was performed. Data collection was performed from March to June 2020 through the available manufacturers' websites. The data of 1473 LED horticultural luminaires were obtained, representing the lighting solutions of 161 horticultural LED manufacturers. Luminaires' data were collected by using a template format (spreadsheet), which included the following database entries, allowing an organization of the data in a tabular form: (a) company name, (b) company country, (c) website link, (d) contact email, (e) luminaire model name, (f) luminaire typology, (g) input voltage, (h) input frequency, (i) power use, (j) Photosynthetic Photon Flux (PPF), (k) efficacy, (l) Photosynthetic Photon Flux Density (PPFD), (m) ingress protection, (n) hours of rated life and (o) additional information. Concerning the mentioned entries, in the case of companies presenting branch offices in multiple countries, the headquarters' location was deemed as representative of the company's country. Moreover, LED horticultural luminaire typologies were listed according to outer appearance (e.g., rounded LEDs, linear LEDs, panel LEDs and others) in order to further classify them. The corresponding lamp metrics and/or performance values (e.g., input voltage, input frequency, power use, PPF, efficacy, PPFD, ingress protection and hours of rated life) were compiled through their technical data sheets (when available) or website information. Furthermore, some enterprises not reporting data within their website were contacted through email to obtain the corresponding datasheets of their products. If none of the technical data were available, the LED lighting system was excluded from the study. For those cases in which the company provided a range value for any of considered parameters, the highest value was selected as the reference. Details on LED luminaires (e.g., luminaire light output degradation L90, L80 or L70 according to IES LM-80) were added in additional information entries. The mentioned specific inputs allowed the filtering of database results to facilitate searching, depending on criteria of interest and preferences.

Microsoft Excel was employed for the analysis of the collected data. The presentation of the results was carried out through the figures and tables previously organized and the textual analysis linked to the literature review and the purpose of the study. Due to the frequent advances in LED technology and quick changes in the horticulture lighting industry [26], the results should be considered as an indicative of the time in which the research was developed.

\section{Results and Discussion}

\subsection{Business Growth Trend and Global Distribution of LED Lighting System Manufacturers}

According to the Annual LED and Lighting Industry Directory [27], the global market of the LED and light industry is highly dominated by Europe (3700 enterprises), followed by America (1100) and Asia (980), while the presence in the market of Australasia and Africa is still low (170 and 60, respectively). The LED lighting system industry is continuously growing through multiple applications, out of which, today, general lighting constitutes the majority [28]. Research focused on the public lighting systems of Rome (Italy) has highlighted that the transition to the use of LED lighting sources instead of old traditional lamps is economically and financially viable, in addition to contributing other key advantages (e.g., reduction of energy consumption, lower $\mathrm{CO}_{2}$ emissions, reduction of light pollution, etc.) $[29,30]$. On the other hand, in the horticultural sector, the LED lighting industry is experiencing an emerging trend, with expectations of achieving full market expansion in the coming years (due to high value/high compound annual growth rate) [28]. Accordingly, the suitability of LED technology for plant growth has determined its application as a main component of vertical farming, with it being progressively chosen by growers to improve plant light environments as more lighting enterprises have entered the industry [31]. Moreover, the public interest in LED technology for horticultural purposes has been confirmed in the last years by the recorded rise of researches number for terms such as "LED horticulture" and "LED grow lights" on the Google database, besides a higher number of academic publications on PubMed using the same keywords [32]. Thus, the global LED horticultural lighting market experienced growth ranging 25\% to 30\% (USD 369 million) in 2019, 
with an increase of 31\% year-on-year [33]. In this context, the horticultural LED lighting system market presents a promising outlook, with an expectation for growth from USD 576 million reported in 2016 to USD 5.11 billion by 2022 [34]. Furthermore, the indoor vertical farming industry, where LED lighting systems are a key factor, is poised to experience a boom from 2022 to 2027, reaching a total market size of more than USD 17 billion by 2027 [35]. Accordingly, the era of LED lighting systems for plant cultivation as a globally emerging industry has just started, with many lighting firms already entering the horticulture sector to provide new commercial products [36].

In this study, 301 LED lighting system manufacturers distributed worldwide were identified (https://www.google.com/maps/d/edit?mid=1OnSDq6d2bQ6oGciTUJkS6Uyn03woD3jb\& usp=sharing), out of which 70\% were located in Europe and North America (Figure 1). European and North American lighting companies were the first to create a business related to the application of artificial lighting technology in the horticultural sector, and already, in 2006, in the Netherlands, a greenhouse area of 2,000 ha equipped with supplementary lighting systems existed [7,36]. To date, Europe has been the greatest horticultural LED lighting system-producing region worldwide, hosting $40 \%$ of horticultural LED lighting system manufacturers, followed by North America (29\%), Asia Pacific (22\%), Latin America (5\%), Africa and the Middle East (2\%) (Figure 1). Looking at the national rankings, the United States (US) and Canada represented the first and third positions in terms of global market size, with shares of $21 \%$ and $8 \%$, respectively (Figure 1 ). The beginning of the legalization of cannabis cultivation and sale in several states of the US since 2012, as well as the decision of the Canadian government to allow recreational cannabis use and production in 2018, has boosted the cannabis industry [37], with consequences also for LED lighting system businesses, as some manufacturers focus on cannabis cultivation only. In terms of LEDs not for specific horticultural use, the Asian market covers most of the production of diode packages and the mining of LEDs' raw materials (e.g., indium, yttrium, cerium and gallium) [38]. According to the data recorded in this study for the Asia Pacific region, China hosts $14 \%$ of the LED lighting system manufacturers, consequently being the second nation in the global market (Figure 1). The industry is highly concentrated in the Southern East area of the country, specifically in the region of Shenzhen.

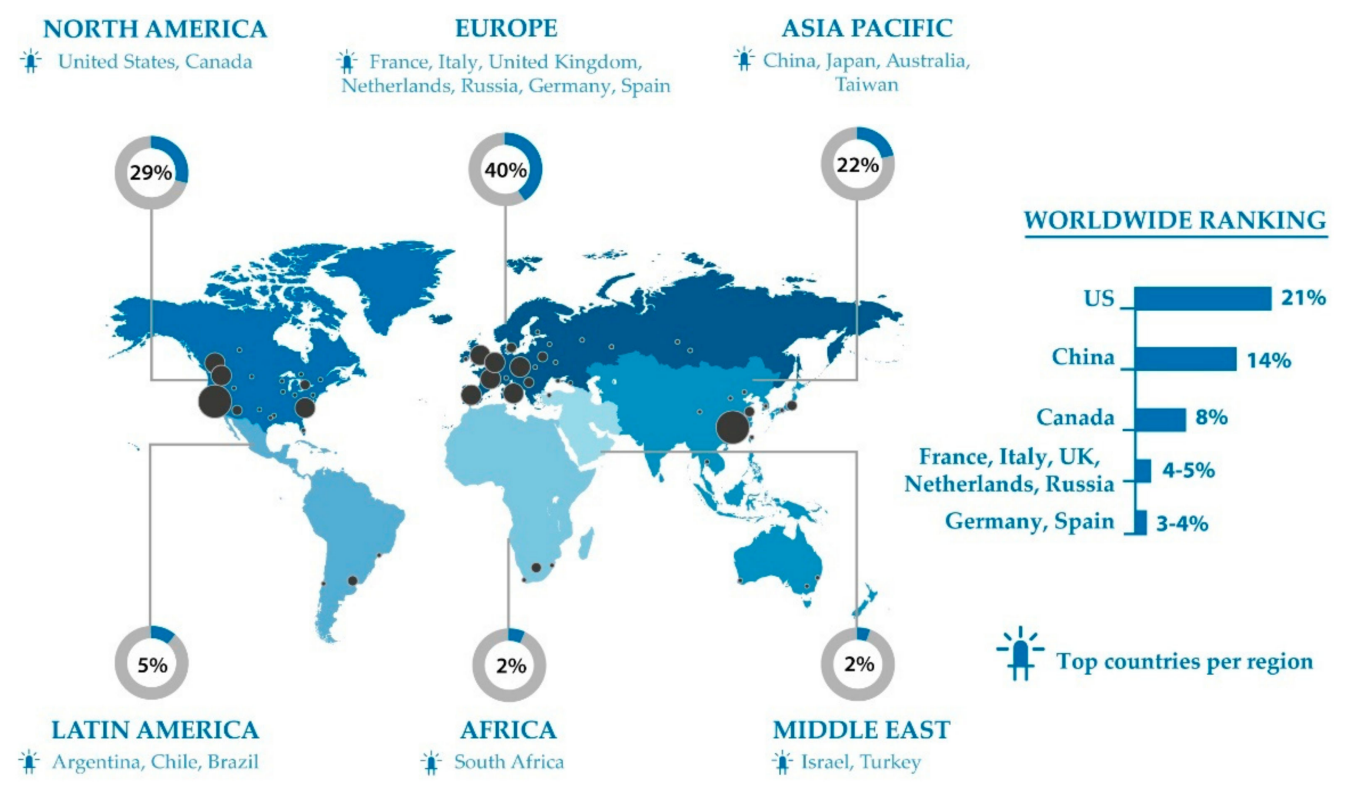

Figure 1. Global distribution of horticultural LED manufacturers.

The African market is monopolized by South Africa, while Israel and Turkey are the highlighted countries for the Middle East region. Additionally, many governments of developing countries are prioritizing the growth of the horticulture sector as a strategy for export diversification and poverty reduction, which has already led to tripled and quadrupled values of horticultural exports, respectively, 
for Latin America and Africa over the past 20 years [39]. Therefore, the LED lighting system market can be promoted in these regions, from the perspective of new and sustainable horticulture applications in the future.

\subsection{Horticultural LED Luminaire Typologies and Area of Production}

The rapid improvement of lighting technology and luminaire efficiency is expanding the horticultural lighting market to a wide range of LED lighting solutions [24]. When designing LED lighting systems for plant cultivation, manufacturers should consider the type and arrangement of the used LED devices, mechanical packaging, thermal management, optics and electrical features [2]. Depending on lamp shape and due to the low radiant heat emitted from LED luminaires [2], the light source position in relation to the plant canopy can be different. Over-head light is the most frequent lighting device setting on the market; however, some specific configurations of linear bars can be implemented for middle canopy lighting (e.g., intracanopy lighting or interlighting), which can also be installed as under-canopy devices [40].

In this research, 1,473 LED horticultural luminaires were listed and organized into four different categories according to outer appearance: rounded LEDs, linear LEDs, panel LEDs and others (Figure 2). Consequently, an analysis of the luminaire typologies according to their presence in the market was performed.

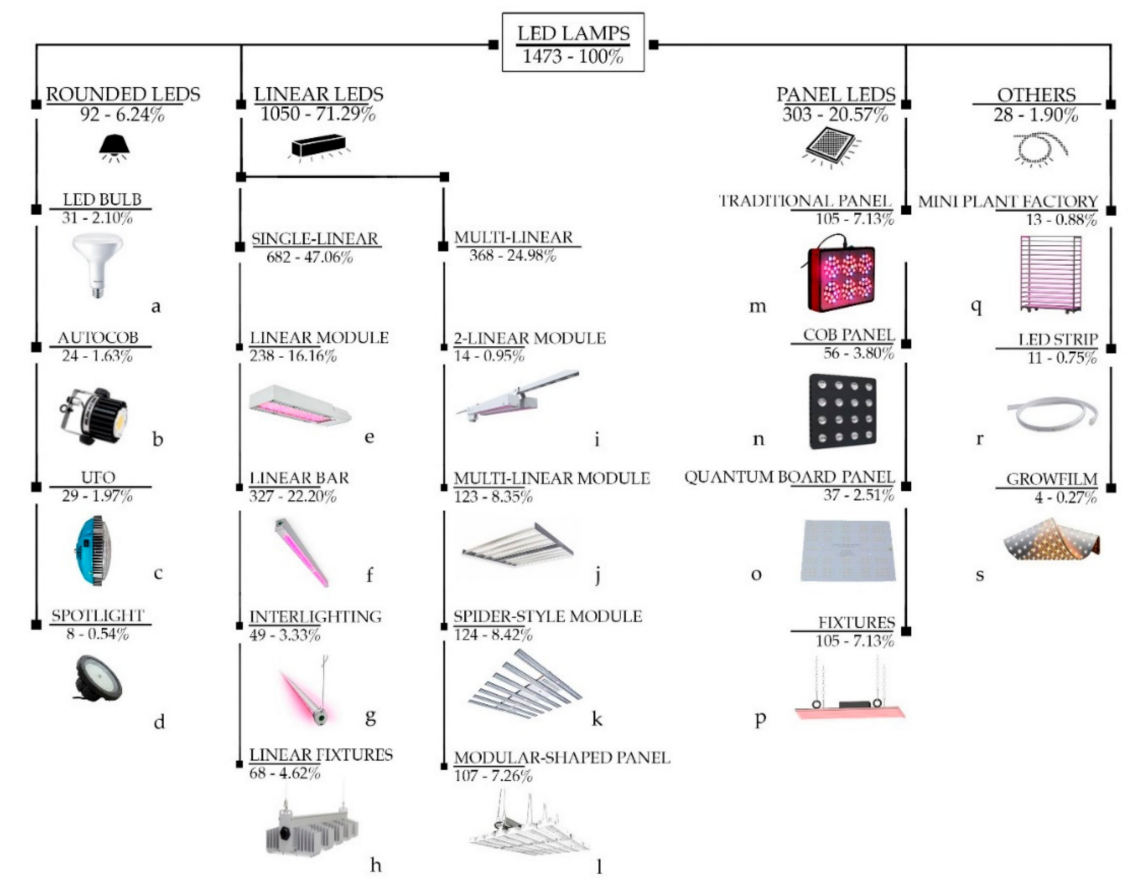

Figure 2. Horticultural LED luminaires typologies grouped according to outward surface and market share. Rounded LEDs: (a) LED bulbs (Philips, Amsterdam, Netherlands); (b) AutoCOB (Blackcob, Las Condes, Chile); (c) UFO (Cidly, Shenzhen, China); (d) spotlights (Spectrum King LED, Los Angeles, United States). Linear LEDs: (e) linear modules (Philips, Amsterdam, Netherlands); (f) linear bars (Philips, Amsterdam, Netherlands); (g) interlighting (Philips, Amsterdam, Netherlands); (h) linear fixtures (Sanlight, Bludenz, Austria); (i) two-linear modules (Lumigrow, Emeryville, United States); (j) multi-linear modules (Gavita, Aalsmeer, Netherlands); (k) spider-style modules (Illumitex, Austin, United States); (1) modular-shaped panels (Ledeven, Ternay, France). Panel LEDs: (m) traditional panels (Cidly, Shenzhen, China); (n) COB panels (Piranha, Santiago, Chile); (o) quantum board panels (Horticulture Lighting Group, Qualicum Beach, Canada); (p) fixtures (Flytech, Belluno, Italy). Others: (q) mini plant factories (Bever Innovations, Zierikzee, Netherlands); (r) LED strips (J\&C Lighting, Hangzhou, China); (s) grow films (Heilux, Eden Prairie, United States). 
The rounded LED typology, which represents $6 \%$ of the total cases, was further classified into four sub-typologies: LED bulbs, AutoCOB, UFO (disc-shaped LED luminaire system) and spotlights (Figure 2). The LED bulb typology is usually used to illuminate indoor gardens or residential areas [41], as a source with a generally low light output, therefore not being properly adapted for covering broad planted surfaces [15]. However, the technological advances in new rounded LED systems equipped with high-density chip-on-board technology (COB), also named AutoCOB, could allow the overcoming of the bulb limitations. Accordingly, these systems can be used for supplying high light intensity in spaces where plant canopy is absent, being furthermore applicable to different cultivation systems for maintaining proper light quality and productivity [42]. Their availability in the international market is still limited (Figure 2). Furthermore, the market category also considers UFO LED luminaires, with a disc-shaped configuration, as well as spotlight typologies, whose presence in the horticultural LED growing market is, however, quite scarce according to data collected (Figure 2).

The most important LED lighting system category, representing $71 \%$ of the total cases, turned out to be the linear LEDs, which, in the present research, was further divided into single-linear LED systems (47\%) and multi-linear LED systems (24\%) (Figure 2). Several applications of these lighting systems can be found in the LED industry, whether for research facilities, vertical farms, side-canopy or intra-canopy lighting, sole lighting or supplemental lighting solutions [43].

The single-linear LED typology was further divided in four sub-typologies, namely, linear bars, linear modules, interlighting and linear fixtures (Figure 2). Linear bars are the most common LED lamp typology worldwide (22\% of the total cases) (Figure 2). These LED systems, also referred as TLEDs, usually consist of several bars installed side-by-side in order to provide a uniform light distribution over the canopy [2] without releasing excessive heat, therefore allowing them to be placed right above the plant canopy in vertical farming systems, tissue culture rooms and growth chambers [44]. More sophisticated luminaires are represented by linear modules (16\% of the total cases) (Figure 2 ), frequently adopting a linear and rectangular shape ideal for greenhouse supplemental or indoor "high-bay" type lighting, which should be configured with slim shapes in order to avoid sunlight interception in greenhouses [45]. A recent LED lighting application obtaining research interest for the cultivation in greenhouses of dense high-wire crops is LED interlighting systems ( $3 \%$ of the total cases) (Figure 2), which provide light in the middle part of plant canopy and foster yield increases [46]. The linear fixture typology comprises a variety of LED luminaires with different designs but following a linear configuration. These systems are characterized by bigger dimensions than those of common linear modules and normally present specific design features used by companies to offer exclusivity related to functional, configurational or aesthetic purposes.

The multi-linear LED typology, usually composed of contiguous units of single LEDs (bars or modules) assembled as a unitary lighting system, was further divided in four sub-typologies, namely, two-linear modules, multi-linear modules, spider-style modules and modular-shaped panels (Figure 2). Among the identified typologies, multi-linear modules, spider-style modules and modular-shaped panels represent similar shares of the market (around $8 \%$ of the total cases), while the two-linear module configuration is still uncommon (Figure 2). Multi-linear modules, usually composed of several linear bars, are highly promoted for multilayer cultivation systems due to their slim shape and potential application for the full-cycle cultivation of leafy greens and microgreens [47]. In the same way, the spider-style module configuration, characterized by individual diodes spread out on "arms" imitating a spider's body, are widely used in controlled environmental agriculture and multi-tier farming environments, also being promoted for full-cycle commercial cannabis cultivation [48]. Moreover, modular-shaped panels are characterized by a modular design, which makes them suitable for illuminating large greenhouse cultivation areas [44].

Panel LEDs are composed by LEDs distributed on a thin plate that emit light over a large surface area. These panels show a remarkable presence in the market, accounting for $21 \%$ of the total cases (Figure 2). Most of the LEDs included within this category are traditional panels, intended as standard LED lighting solutions used for indoor lighting and specifically designed for cannabis production [49]. 
Chip-on-board (COB) panels are characterized by containing multiple LED chips within a small area with strong lenses to direct light down to the plant. Quantum board panel LEDs are large circuit boards across which LEDs are distributed in several string configurations, firstly introduced by the company Horticulture Lighting Group [50], with their nomenclature afterward being adopted to classify similar boards. Finally, fixture typology comprises different panel or planar arrangements not suitable to be categorized in other LED systems due to their particular design.

The last identified category in the study-namely, other, in Figure 2-includes all those lamp typologies that are not very frequent in the market and accounts for $2 \%$ of the total cases. Among them, the LED strip typology is represented by flexible lighting solutions of variable lengths, which can be placed in both vertical and horizontal positions for sunlight supplementation or substitution [51,52]. Other solutions in the form of flexible growing films have also been developed, characterized by an adaptable disposition surrounding plants [53]. Some manufacturers also offer small indoor cultivation systems with several layers, often named as mini plant factories, which are already integrated with their own LED lighting system and mainly used for laboratory research, tissue culture or food production [54,55].

It was then assessed whether the typology of LED horticultural luminaires could vary depending on the location where manufacturing took place. Accordingly, the research explored the main areas of production of each luminaire typology (Figure 3).

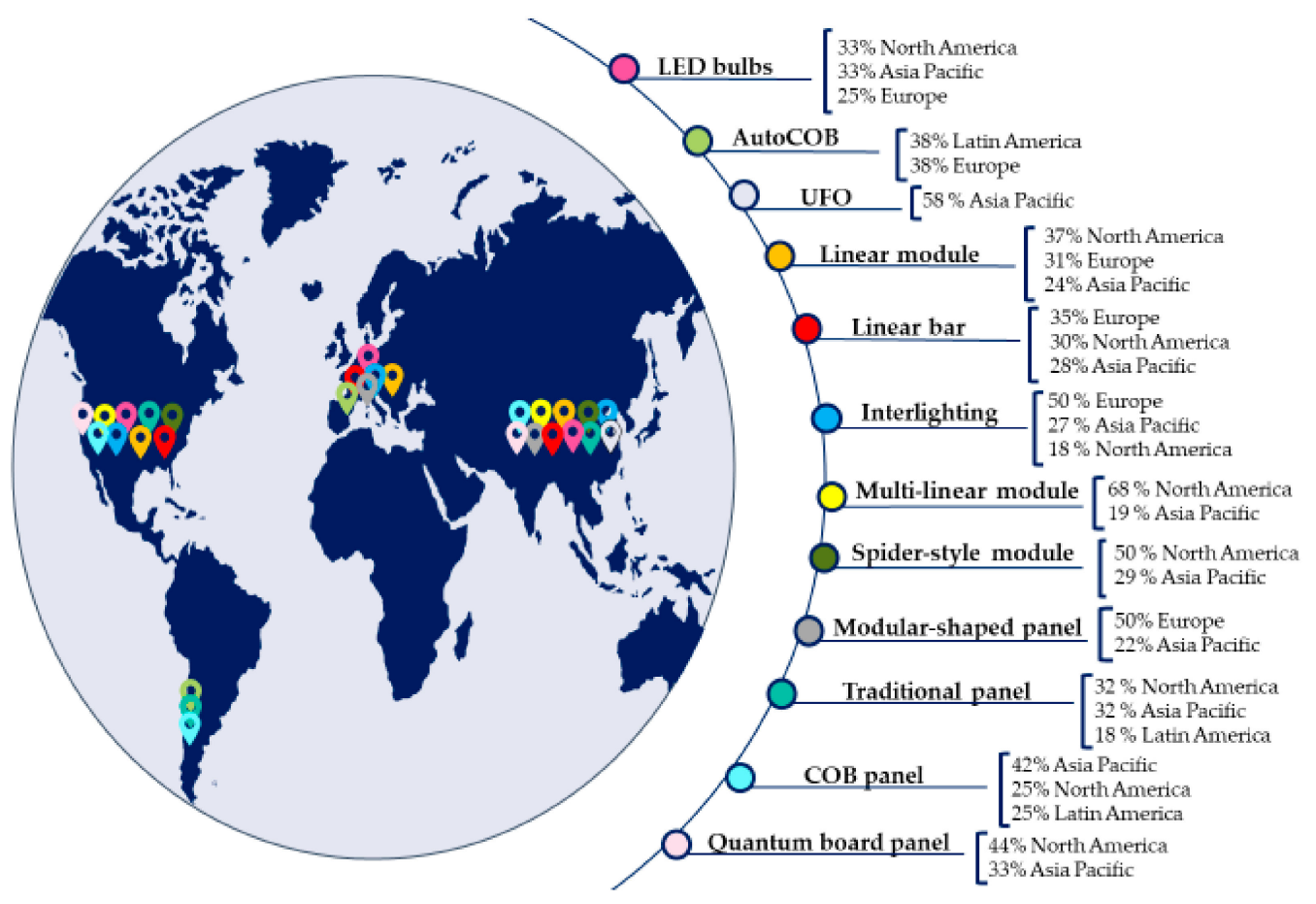

Figure 3. Main production area for each LED luminaire typology.

The results show that European companies are the main producers of lighting typologies employed as supplemental lighting in greenhouses, such as interlighting lamps (50\%), modular-shaped panels $(50 \%)$ and linear modules (37\%). Greenhouse supplemental lighting devices are relatively common in European countries such as the Netherlands, where natural sunlight is scarce during certain periods of the year [31]. On the other hand, North American companies emerged for the production of lamps for indoor cultivation in the absence of sunlight, such as multi-linear modules (68\%), spider-style modules $(50 \%)$ and quantum board panels $(44 \%)$. These solutions are appropriate for the indoor and vertical farming industry, a sector that, over the past years, has been gaining attention from investors, inventors and entrepreneurs across North America [26]. Panel LED typologies, including COB panels 
and traditional panels, are mainly developed in the Asia Pacific region, accounting for 42 and 32\% market shares, respectively. These panel solutions are mainly applied by cannabis growers [49].

\subsection{Electricity Use}

\subsubsection{Power Consumption of Luminaires and Their Lighting Environment}

Power consumption is a fundamental aspect of horticultural LED lighting systems, and not only the power consumed by the lighting unit but also the driver and device used to control light quantity and quality (e.g, dimmer or timer) whenever present should be considered [56]. However, the evaluation of consumed power (also called radiant flux) based only on watts (W) could be a useless metric when comparing lighting systems for plant cultivation, since electricity does not provide a qualitative and quantitative measure of the light received by plants. Furthermore, radiometric efficiency (luminaire emission per W) can vary among the LED lighting systems available on the market [57]. When growing plants with artificial lighting systems, higher relevance is generally given to the system output, which focuses on delivering the proper amount of light to the growing area while reducing electrical consumption [57].

The capability of LED lighting systems to control photon emissions allows the design and manipulation of LED light irradiation according to cultivation strategy [58]. In this sense, photosynthetic active radiation (PAR) plays a fundamental role, being often reported and quantified as photosynthetic photon flux (PPF, expressed as $\mu \mathrm{mol} \mathrm{s}^{-1}$ ) or photosynthetic photon flux density (PPFD, expressed as $\mu \mathrm{mol} \mathrm{m} \mathrm{m}^{-2} \mathrm{~s}^{-1}$ ) [59]. However, many LED lighting system manufacturers do not provide these last measurements, since changes can be determined by the distance between the lighting device and plant canopy or by a non-uniform light distribution on the cultivation area [58].

In the current study, available PPF values $(n=1449)$ were evaluated in correlation to electrical power input $(\mathrm{n}=1007)$ for each lamp typology (Figure 4$)$. The results showed that LED bulb systems are characterized by the lowest power consumption and the lowest light output (Figure 4). AutoCOB systems, with similar sizes as compared to LED bulb systems, offer a PPF emission 22.7 times higher (Figure 4). However, these point-source lighting devices are characterized by operation in close proximity to plants due to their low light output compared to other lighting sources, although they do not provide a uniform light distribution [2]. Contrarily to LED bulb systems, spider-style panels are the LED lighting systems delivering the highest PPF levels on the market, with an average of $1367 \mu \mathrm{mol} \mathrm{s}{ }^{-1}$ (Figure 4), making them a suitable choice for high daily light integral (DLI) crops [48]. Considering panel LED systems, similar average light outputs are reported for traditional panels and quantum board panels, although average power consumption showed a 1.3 times lower value for quantum boards. $\mathrm{COB}$ panels are, among the panel category, the ones with the highest power consumption, with an average PPF 1.45 times greater than that of traditional panels (Figure 4). Particularly, AutoCOB and $\mathrm{COB}$ panels are chip-on-board (COB) LED solutions involving several LEDs connected together in various combinations, optically matched under the same primary lens and characterized by high light intensities [60]. Concerning single-linear LED solutions, all light typologies in the category exhibited lower average power consumption (less than $250 \mathrm{~W}$ ), although linear modules offer the greatest average light output (around $650 \mu \mathrm{mol} \mathrm{s}^{-1}$ ) (Figure 4). Moreover, growing films, a recent luminaire system on the market, show values quite similar to those of traditional panel systems for both considered parameters (Figure 4). Finally, considering all horticultural LED lighting system typologies, a strong correlation between light output (PPF) and electrical power input (W) can be observed (Figure 4). To this extent, the ratio between the optical power output (expressed as PPF) and the electrical power input (expressed as W) is described as the LED lighting system efficacy (expressed as $\mu \mathrm{mol} \mathrm{J}^{-1}$ ) and strongly depends on the spectral distribution [61]. Further discussion on current LED luminaires' efficacy is provided in Section 3.5, considering that improvements in single LED efficiencies have been achieved, reaching values of $93,81,77$ and $76 \%$, respectively, for blue, red, far-red and white diodes [61]. 


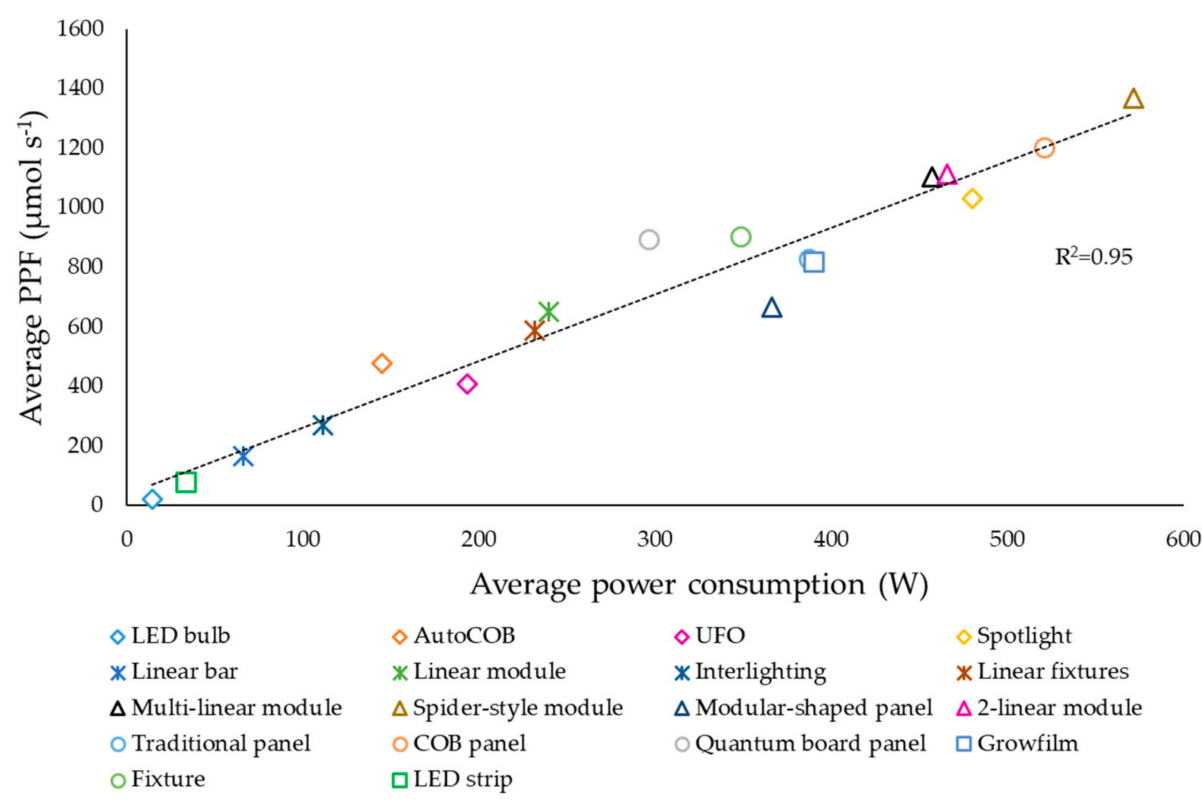

Figure 4. Correlation between average power input $(n=1449)$ and average Photosynthetic Photon Flux (PPF) output $(\mathrm{n}=1007)$ for each lamp typology.

\subsubsection{LED Driver, Dimming and Input Voltages}

LEDs are digital emitters powered with low voltage and mostly operating with direct current (DC). Therefore, drivers (also known as power supplies) are a basic requirement to convert the alternating current $(\mathrm{AC})$ line to voltage and current compatible with LED lighting systems $[2,62,63]$. The most recent LED lighting systems offer control functions such as dimmability, which is a characteristic required to meet the different plant needs, allowing for a precise control of light intensity $[2,64]$. Several drivers' configurations are available to accommodate different LEDs and can be categorized into two main topologies according to driver distribution: lighting systems designed without any power supply onboard or lighting systems that embed the LED drivers onboard $[63,65]$. At the present time, the efficiency of LED drivers ranges from 85 to 95\% [61], allowing low electricity consumption while maintaining good light emission [62].

LED drivers guarantee stable working conditions, which is a fundamental aspect, considering that a small voltage variation can lead to large changes in output power [62]. The voltage requirements of the LED lighting system industry were compiled in the present study, building on the input voltage ranges provided by producers $(n=905)$. The results showed a wide variability range; however, the vast majority of LED lighting system manufacturers operate with input voltage ranges (AC) such as 100-277 $(\mathrm{n}=269), 220-240(\mathrm{n}=118), 120-277(\mathrm{n}=116), 100-240(\mathrm{n}=107), 90-305(\mathrm{n}=45), 120-480(\mathrm{n}=45)$, 100-480 ( $\mathrm{n}=45)$ and 100-305 ( $\mathrm{n}=44)$. These high input voltages are controlled through a driver circuit by two common methods of control: linear dimming, which reduces the DC current flowing through the LEDs, and pulse-width modulation (PWM) dimming, which reduces the percentage of time that the pulse is "on" duty cycle to dim the LEDs [2]. However, depending on whether the lighting system is intended for use in North America, Europe, Asia or somewhere else, different electricity standards will govern the design and testing requirements of horticultural LED lighting systems [66].

\subsection{Lifespan and Lumen Depreciation}

When producing an LED lighting system, special attention should be given to design, manufacturing and operation in order to maximize system lifetime and minimize the decline of the light output [2]. In comparison with other lighting sources, an LED lighting system's lifetime tends to be longer, mainly due to the absence of movable parts or filaments that may break. Accordingly, an LED lighting system's lifetime is mostly defined as lumen maintenance $[67,68]$. The technical lives of LEDs are about 
$100,000 \mathrm{~h}$, although their utilization is generally shorter due to the reduction of luminous flux at the end of their lives [67]. Therefore, an LED lighting system's lifetime is defined as the number of hours at which the emitted light intensity has degraded to a certain percentage from initial intensity [68]. A large number of horticultural LED lighting system manufacturers report the hours-rated lives of their systems as L70, L80 and L90, meaning 30\%, 20\% and 10\% of light output degradation from initial values, respectively. This evaluation is based on a standard LED package test (IES LM-80) that builds on the assumption that projections of luminaire lumen maintenance based on LED depreciation cannot exceed six times the duration in which the LEDs were tested [61].

In this study, only $72 \%$ of the LED lighting system manufacturers identified all over the world report data about lighting device lifespan (Figure 5a). LED lighting system life expectancy is indeed an important parameter for growers for estimating the lamp replacement time and associated costs [69]. Nevertheless, disinformation can cause customers to be misled, and among companies reporting lighting device lifespan, almost half of the manufacturers (45\%) do not provide any information on the light output degradation considered (e.g., L90, L80 or L70) (Figure 5b). On the other hand, L90 is the categorization most frequently employed, accounting for 35\% of LED lighting system manufacturers (Figure 5b). Considering the wide data availability for LED lighting systems in this category $(n=402)$ and building on their light output projection over time, a deeper analysis in this section was performed. Figure $5 \mathrm{c}$ shows that the vast majority of L90 lamps are in the range of 25,000-75,000 $\mathrm{h}(93 \%)$. Morrow [15] mentioned that LED technologies were rated to maintain $70 \%$ of their original luminous output after 50,000 h. Today, the horticultural LED lighting systems on the market have an average predicted lifetime of $45,000 \mathrm{~h}$ in terms of keeping at least $90 \%$ of the initial output (Figure 5c). Moreover, most of the L80 LED lighting systems $(80 \%)$ are within the lifetime range of 50,000-75,000 h, while some companies offer LED lighting systems claiming lifetimes higher than $150,000 \mathrm{~h}$, although based on the more generous L70 standard [70,71] (Figure 5c).

Lifespan data availability

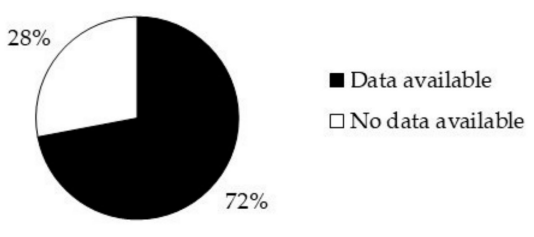

(a)

Lifespan category

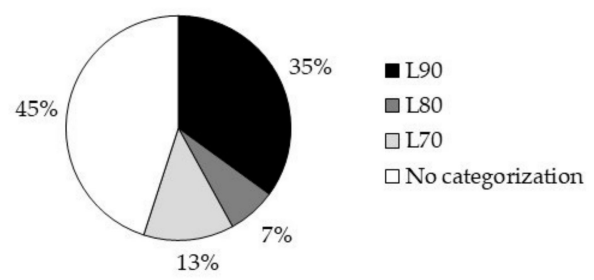

(b)

\section{Hours ranges according to $\mathrm{L}$ standards}

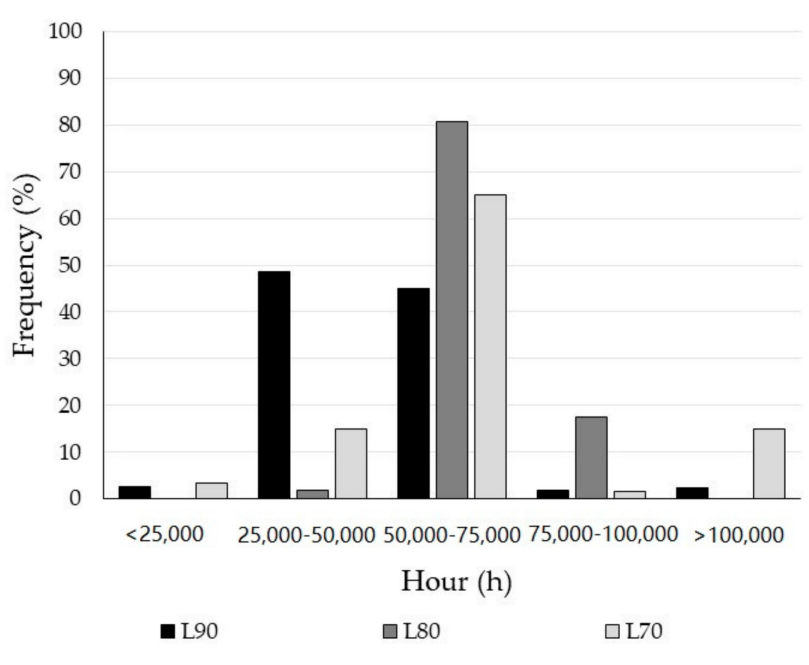

(c)

Figure 5. Lifespan in worldwide LED horticulture industry. (a) Lifespan data availability among worldwide-distributed manufacturers $(n=161)$. (b) Lifespan category based on L standard among companies reporting hours-rated life $(n=116)$. (c) Frequency in hours ranges of luminaire lifespans according to their L standards $(n=519)$.

Furthermore, given that the lifetimes of many LED lighting systems are not categorized (Figure 5b), in the current research, the average lifetime per horticulture LED lighting system typology was analyzed considering the L90 standard. However, some limitations could be found, as not all the collected 
typologies were available in this standard; furthermore, a consistent number of luminaires for some typologies could not be achieved to perform a proper evaluation. Table 1 shows that both linear modules and linear bars have average lifetimes 1.9 and 1.5 times higher compared to those of LED bulb systems. This is in accordance with a study by Nardelli et al. [11], who compared the lifespans of the main types of general lighting, concluding that linear LEDs are the ones with longer lifespan. Moreover, multi-linear and spider-style modules presented the highest hours-rated lives among the analyzed LED lighting systems, respectively, resulting in expected L90 average lifetimes of 49,244 and $53,160 \mathrm{~h}$ (Table 1$)$.

Table 1. Average L90 lifetime according to LED luminaire typology, reporting available data $(\mathrm{n}=402)$.

\begin{tabular}{cc}
\hline LED Lighting System Typology & Average L90 Lifetime (h) \\
\hline LED bulb & 23,846 \\
Linear bar & 36,660 \\
Linear module & 46,517 \\
Interlighting & 41,187 \\
Modular-shaped panel & 46,560 \\
Multi-linear module & 49,244 \\
Spider-style module & 53,160 \\
\hline
\end{tabular}

Thermal Management and Ingress Protection

Horticultural LED lighting systems' lifetimes can be adversely affected by several components (e.g., drivers, fans and connectors) and parameters, such as high LED junction temperatures, poor current regulation, manufacturing quality, vibrations and operating environment [2]. The working temperature is the main parameter influencing life and LED lighting system efficiency, being reported that when temperature is increased by $10^{\circ} \mathrm{C}$, the LED lighting system life is halved, while light output decreases by $3 \%$ to $8 \%$ [67]. Consequently, cooling systems are needed to dissipate heat, since cooler LED lighting system working temperatures result in improved light intensity and a longer lifetime [24]. Therefore, while optimal thermal management will result in higher manufacturing costs, it will also favor higher system efficacy and lifespan [61].

Plant cultivation environments are often very humid and can be subjected to several corrosion factors (e.g., chemical or biological). Therefore, the protection of active and passive components of LED lighting systems is one of the most significant challenges associated with LED horticultural applications [66]. The LED lighting system IP (Ingress Protection) ratings were collected in this study, defined as the sealing of electrical components protecting against the intrusion of external influences or conditions such as solids, dust, mechanical contact and water [72]. The IP rating consists of two numbers, where the former indicates protection against solid objects on a scale from 0 (none) to 6 (completely dust-tight), while the latter indicates moisture protection on a scale from 0 (no protection) to 8 (can be immersed in water under pressure for extended periods of time) [73]. The most common IP rating provided by the horticultural LED lighting companies addressed within this study is IP65 (43\%, $\mathrm{n}=419$ ), meaning the systems are dust-tight and have protection against water jets from any angle. The following ratings are IP66 $(26 \%, \mathrm{n}=254)$ and IP67 $(10 \%, \mathrm{n}=101)$ (Figure 6), meaning the systems are dust-tight and the luminaires are temporarily immersible in water [73]. Better-waterproofed LED lighting systems have been developed in order to obtain higher system safety and lifetime extension, with systems offering the highest IP68 protection rating already being available $(n=2)$ [74]. 


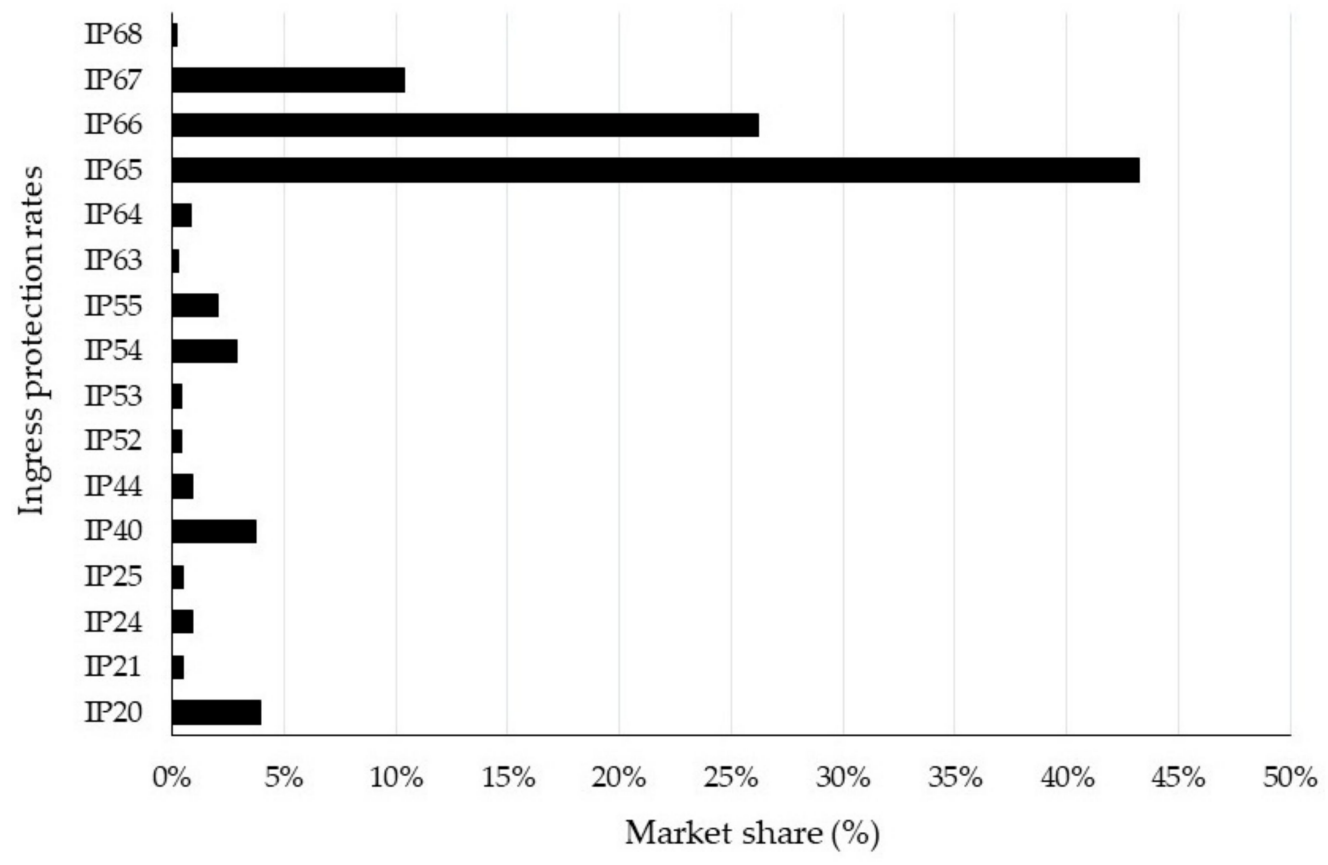

Figure 6. Frequency of ingress protection rates among LED horticultural luminaires $(\mathrm{n}=970)$.

\subsection{Energy Use Efficiency}

Creating a suitable lighting environment for plant growth applications plays an important role in the horticultural LED lighting system industry. Optimal light features for crop growth and development need to be matched by horticulture LED lighting system manufacturers, who should also target the reduction of electricity consumption by electrical efficiency maximization [25]. The efficiency of LED luminaires is determined by LED package efficiency multiplied by other factors such as current droop, thermal droop, driver inefficiencies and optical losses [61]. Moreover, lighting system efficiency in horticulture is based on photosynthetic photon efficacy (expressed in $\mu \mathrm{mol} \mathrm{J^{-1 }}$ ). The efficacy of LED lighting systems in converting electricity into light is increasing year by year [75]. In 2014, Nelson and Bugbee [24] showed that most efficient HPS lamps had efficacy values ranging from 1.6 to $1.7 \mu \mathrm{mol} \mathrm{J}^{-1}$, quite similar to LED luminaires' efficacy, ranging from 0.8 to $1.7 \mu \mathrm{mol} \mathrm{J}^{-1}$. Today, LED lighting systems are more efficient compared to the other lighting sources employed in horticulture [23]. Kusuma et al. [61] estimated the maximum potential LED luminaire efficacy for the latest technology available on the market, reporting that an LED lighting system with $90 \%$ of red diodes and $10 \%$ of blue diodes could achieve a possible efficacy of $4.1 \mu \mathrm{mol} \mathrm{\textrm {J } ^ { - 1 }}$.

Lighting manufacturers are already adopting the metrics used in the horticulture sector, as demonstrated by an increasing trend of companies reporting the photosynthetic photon efficacy of luminaires [18]. Nevertheless, among the cases included in this study, $30 \%$ of the LED lighting system producers still do not report the photosynthetic photon efficacy of lamps (Figure 7a), with a large number of companies from Russia and South American countries inside this group. Additionally, it was found that the vast majority of current LED luminaires $(70 \%, n=663)$ present efficacy values ranging from 2.0 to $3.0 \mu \mathrm{mol} \mathrm{J}^{-1}$ (Figure $7 \mathrm{~b}$ ), in accordance with previous indications by Kusuma et al. [61]. New advances in LED technology are driving higher lamp efficacies, with $8 \%(n=83)$ of the luminaires available on the market reporting an efficacy higher than $3.0 \mu \mathrm{mol} \mathrm{J} \mathrm{J}^{-1}$ and $31 \%(\mathrm{n}=296)$ with such ranging 2.5 to $3.0 \mu \mathrm{mol} \mathrm{J}^{-1}$. In a report by Radetsky et al. [76], the highest efficacy values for HPS and LED luminaires were reported to be 1.72 and $2.64 \mu \mathrm{mol} \mathrm{J}{ }^{-1}$, respectively. Pinho et al. [25] estimated that by the current year 2020, the efficacy values of LED lighting systems would have doubled as compared with those of HPS lamps, and their estimations are close to being fulfilled, as market LED lighting system manufacturers have already reported values reaching and surpassing such claims [77-79]. 
Efficacy data availability

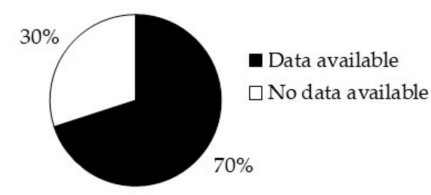

(a)

Number of luminaires per range of

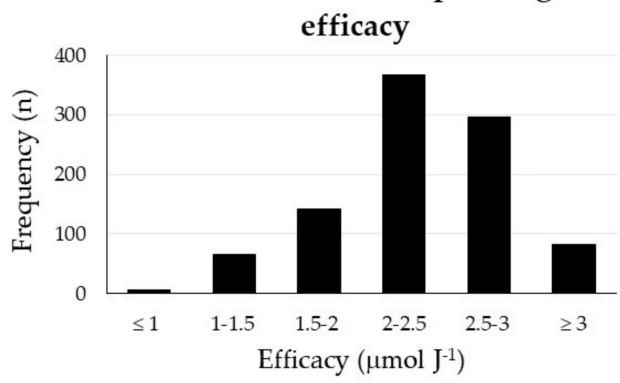

(b)

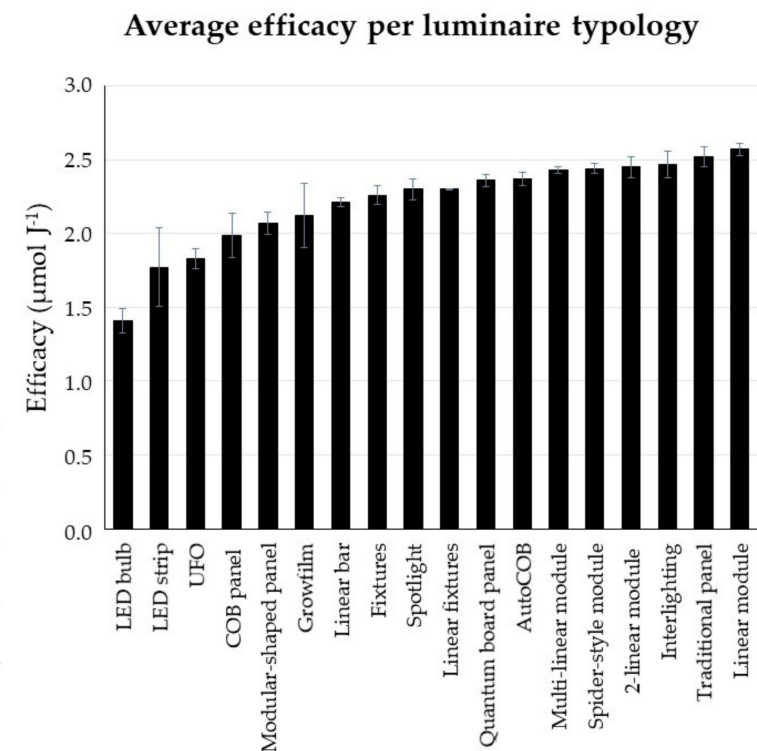

(c)

Figure 7. Efficacy in worldwide LED horticultural industry. (a) Efficacy data availability among worldwide-distributed manufacturers $(n=161)$. (b) Frequency ranges of luminaire efficacy $(n=959)$. (c) Average efficacy according to luminaire typology (mean value \pm standard deviation).

Furthermore, a detailed analysis of the efficacy values of each lamp typology available on the horticultural market was performed (Figure 7c). LED bulb systems were the luminaires showing the lowest average efficacy values, followed by LED strip systems. The small dimensions of these devices (which are not commonly used in commercial applications) could be a reason for their worse electrical conversion. On the other hand, linear modules, widely employed for supplemental lighting in greenhouse cultivation, show the highest average efficacy values $\left(2.6 \mu \mathrm{mol} \mathrm{J}^{-1} ; \mathrm{n}=238\right)$, quite close to those of interlighting systems $\left(2.5 \mu \mathrm{mol} \mathrm{J}^{-1} ; \mathrm{n}=43\right)$. Traditional panels also exhibited high efficacy values $\left(2.5 \mu \mathrm{mol} \mathrm{J}^{-1} ; \mathrm{n}=18\right)$. However, it should be mentioned that only a few of the manufacturers producing this type of lamp actually provided their efficacy values. In comparison, COB panels, which showed higher light outputs (Figure 4), present a lower efficacy. Concerning multi-linear and spider-style modules, their higher and similar efficacy $\left(2.4 \mu \mathrm{mol} \mathrm{J}^{-1} ; \mathrm{n}=109\right.$ and 89 , respectively) can be seen as a result of the rise of vertical farming businesses [31], where these LED lighting system typologies are often applied. Besides, linear bars showed an average efficacy of $2.2 \mu \mathrm{mol} \mathrm{J}^{-1}(n=233)$. The efficacy values for LED lighting systems will continue to increase in the coming years; nevertheless, other parameters such as durability, drivers, spectral emission and cost will also influence the efficacy values of horticultural LED lighting systems [61]. Therefore, it will be necessary to keep up with their evolution.

\section{Conclusion and Future Prospects}

The horticultural LED lighting market is expected to experience potential growth in the coming years. Today, the industry is highly concentrated in Europe and North America. The United States, China and Canada are the biggest manufacturers of LED grow lights, occupying almost half of the market, while in Europe, their production is quite uniformly distributed among countries. Nevertheless, several emerging countries are also opting to develop their horticultural lighting sectors, which could represent a new opportunity for companies to position themselves as important players in locations where the sectors are not widely developed. Consequently, it can be inferred that the industry is globally emerging, with sector evolution associated with the extensive availability of LED grow luminaires offered by the market. 
These lighting technologies are available in a wide range of configurations, offering the possibility to be adaptable to many different plant growing environments. Linear LEDs are the category among the luminaire typologies with a higher presence in the market, being mainly employed for indoor farming and supplemental lighting greenhouse cultivation. Moreover, technological advances are leading to different lamp applications, not only with over-head placement but also as intracanopy or multilayer lighting solutions. New LED grow luminaires with different configurations and improved performance are being continuously developed. The typology design of each LED grow lamp can be influenced by the location of the manufacturer. Accordingly, European companies have a strong influence on the production of greenhouse supplemental lighting lamps, probably as a result of the intensive greenhouse production and the lower reachable solar radiation in the Northern countries. On the other hand, North American companies emerged for the production of indoor farming lighting solutions, such as multi-linear or spider-style modules, among others, as a possible consequence of the higher development of vertical farms and plant factories and a step forward to control the associated markets. Moreover, the Asia Pacific region encompasses a great part of the production of the panel LED typology.

LED luminaires offer appropriate light output per power consumption, the dimensions of the lamps being a good indicator of these parameters, as the smaller the size, the lower the power used and PPF. Consequently, the design of the luminaire can represent an important aspect for predicting its light output and to adapt it to plant requirements.

An LED lighting system's life expectancy is also an important parameter for growers for estimating the lamp replacement time and associated costs. Nevertheless, a large number of LED manufacturers $(28 \%)$ do not report data about their lighting device lifespans. Additionally, among the manufacturers reporting the lifetimes of their lamps, almost half of the manufacturers $(45 \%)$ do not provide any information on the light output degradation considered (e.g., L90, L80 or L70), which leads to misinformation for growers. Concerning the lifespans of LED luminaires currently on the market, there are 10 and $30 \%$ losses of light output after 45,000 and 60,000 working hours on average, respectively. Besides, the plant cultivation environment is characterized by a humid atmosphere and can be subjected to several corrosion factors. Accordingly, the vast majority of horticultural LED manufacturers offer their luminaires with the highest standards of protection against external influences or unfavorable moisture conditions.

When using artificial lighting for plant cultivation, energy saving is an important factor for growers for controlling costs. Lighting manufacturers are already adopting the metrics used in the horticultural sector, although about $30 \%$ of global LED lighting system producers still do not report the photosynthetic photon efficacy of lamps. The great majority of worldwide LED lighting systems had efficacy values ranging 2.0 to $3.0 \mu \mathrm{mol} \mathrm{J}^{-1}$, while new advances in LED technology are driving higher lamp efficacies. More efficient lighting techniques are essential to improve the sustainability and profitability of crop production. Additionally, the technological advances in the greenhouse industry are mainly represented by two of their supplemental lighting typologies (linear modules and interlighting lamps), featuring the highest average efficacy values on the market.

In the coming years, LED lighting systems will play an important role in yield achievements in controlled indoor environments. These systems are particularly suitable for vertical farming purposes, in which an efficient use of space is realized by cultivating several crop species with high densities on multiple layers. The art of growing plants with artificial lighting is evolving together with new digital and smart technologies for vertical farms, small indoor gardening systems, academic research, sensor technology and cloud computing. Current LED lighting system manufacturers already offer smart lighting sources supported by wireless connection and embedded software [20,80]. Plant health issues can also be identified by visual sensing through the incorporation of cameras, attached or in close proximity to LED lighting systems, able to work with algorithms for the early detection of plant stress symptoms. Therefore, it is expected that LED horticultural businesses will take advantage of technology evolution over the coming years. Furthermore, software businesses for LED lighting 
systems will play a major role, allowing the implementation of the remote control and monitoring of lighting factors for optimal crop growth.

Author Contributions: Conceptualization, F.O. and G.P.; methodology, F.O., G.P. and I.P.; software, I.P.; validation, E.A. and G.P.; formal analysis, G.P.; investigation, I.P. and E.A.; resources, F.O. and S.Q.; data curation, I.P. and E.A.; writing —original draft preparation, I.P.; writing—review and editing, E.A., G.P., F.O., S.Q. and G.G.; visualization, E.A.; supervision, G.G. and F.O.; project administration, F.O.; funding acquisition, F.O. All authors have read and agreed to the published version of the manuscript.

Funding: The research leading to this publication has been supported by a collaboration between the University of Bologna Alma Mater Studiorum and the Fondazione Eni Enrico Mattei.

Acknowledgments: The authors express gratitude to Charlotte Rambla for contributing in the implementation of the database of LED manufacturers.

Conflicts of Interest: The authors declare no conflict of interest.

\section{References}

1. Mangon, M.H. Production of the green matter of leaves under the influence of the electric light. Lond. Edinb. Dublin Philos. Mag. J. Sci. 1861, 22, 327-328. [CrossRef]

2. Mitchell, C.A.; Dzakovich, M.P.; Gomez, C.; Lopez, R.; Burr, J.F.; Hernaández, R.; Kubota, C.; Currey, C.J.; Meng, Q.; Runkle, E.S.; et al. Light-emitting diodes in horticulture. Hortic. Rev. 2015, 43, 1-87. [CrossRef]

3. Bantis, F.; Smirnakou, S.; Ouzounis, T.; Koukounaras, A.; Ntagkas, N.; Radoglou, K. Current status and recent achievements in the field of horticulture with the use of light-emitting diodes (LEDs). Sci. Hortic. 2018, 235, 437-451. [CrossRef]

4. Higuchi, Y.; Hisamatsu, T. Light Acts as a Signal for Regulation of Growth and Development. In $L E D$ Lighting for Urban Agriculture; Kozai, T., Fujiwara, K., Runkle, E.S., Eds.; Springer: Singapore, 2016; pp. 57-73. [CrossRef]

5. Olle, M.; Viršile, A. The effects of light-emitting diode lighting on greenhouse plant growth and quality. Agric. Food Sci. 2013, 22, 223-234. [CrossRef]

6. Singh, D.; Basu, C.; Meinhardt-Wollweber, M.; Roth, B. LEDs for energy efficient greenhouse lighting. Renew. Sust. Energ. Rev. 2015, 49, 139-147. [CrossRef]

7. Heuvelink, E.; Bakker, M.J.; Hogendonk, L.; Janse, J.; Kaarsemaker, R.; Maaswinkel, R. Horticultural Lighting in the Netherlands: New Developments. Acta Hortic. 2006, 711, 25-34. [CrossRef]

8. Kacira, M. Greenhouse Production in US: Status, challenges, and opportunities. In Proceedings of the CIGR Conference on Sustainable Bioproduction-Water, Energy, and Food, Tokyo, Japan, 19-23 September 2011.

9. Rehman, M.; Ullah, S.; Bao, Y.; Wang, B.; Peng, D.; Liu, L. Light-emitting diodes: Whether an efficient source of light for indoor plants? Environ. Sci. Pollut. Res. Int. 2017, 24, 24743-24752. [CrossRef] [PubMed]

10. Sipos, L.; Boros, I.F.; Csambalik, L.; Székely, G.; Jung, A.; Balázs, L. Horticultural lighting system optimalization: A review. Sci. Hortic. 2020, 273, 109631. [CrossRef]

11. Nardelli, A.; Deuschle, E.; de Azevedo, L.D.; Pessoa, J.L.N.; Ghisi, E. Assessment of Light Emitting Diodes technology for general lighting: A critical review. Renew. Sust. Energ. Rev. 2017, 75, 368-379. [CrossRef]

12. Massa, G.D.; Kim, H.; Wheeler, R.M.; Mitchell, C.A. Plant Productivity in Response to LED Lighting. HortScience 2008, 43, 1951-1956. [CrossRef]

13. Bula, R.J.; Morrow, R.C.; Tibbitts, T.W.; Barta, D.J.; Ignatius, R.W.; Martin, T.S. Light-emitting Diodes as a Radiation Source for Plants. HortScience 1991, 26, 203-205. [CrossRef] [PubMed]

14. Barta, D.J.; Tibbitts, T.W.; Bula, R.J.; Morrow, R.C. Evaluation of light emitting diode characteristics for a space-based plant irradiation source. Adv. Space Res. 1992, 12, 141-149. [CrossRef]

15. Morrow, R.C. LED Lighting in Horticulture. HortScience 2008, 43, 1947-1950. [CrossRef]

16. Haitz, R.; Kish, F.; Tsao, J.; Nelson, J. The case for a national research program on semiconductor lighting. In Proceedings of the Annual Forum of the Optoelectronics Industry Development Association, Washington, DC, USA, 6 October 1999.

17. Haitz, R.; Tsao, J.Y. Solid-state lighting: “The case" 10 years after and future prospects. Phys. Status Solidi 2010, 208, 17-29. [CrossRef]

18. Runkle, E.S. Recent Developments in Plant Lighting. In LED Lighting for Urban Agriculture; Kozai, T., Fujiwara, K., Runkle, E.S., Eds.; Springer: Singapore, 2016; pp. 233-236. [CrossRef] 
19. Illumitex. FARMVISIONAI ${ }^{\mathrm{TM}}$ System. Available online: https://illumitex.com/farmvisionai-2/ (accessed on 24 May 2020).

20. Lumigrow. SmartPARTM Software. Available online: https://www.lumigrow.com/smartpar-software/ (accessed on 20 May 2020).

21. ANSI/ASABE S640: Quantities and Units of Electromagnetic Radiation for Plants; American Society of Agricultural and Biological Engineers: St. Joseph, MI, USA, 2017.

22. ANSI/ASABE S642: Recommended Methods for Measurement and Testing of LED Products for Plant Growth and Development; American Society of Agricultural and Biological Engineers: St. Joseph, MI, USA, 2018.

23. Cocetta, G.; Casciani, D.; Bulgari, R.; Musante, F.; Kolton, A.; Rossi, M.; Ferrante, A. Light use efficiency for vegetables production in protected and indoor environments. Eur. Phys. J. Plus 2017, 132, 43. [CrossRef]

24. Nelson, J.A.; Bugbee, B. Economic Analysis of Greenhouse Lighting: Light Emitting Diodes vs. High Intensity Discharge Fixtures. PLoS ONE 2014, 9, e99010. [CrossRef]

25. Pinho, P.; Jokinen, K.; Halonen, L. Horticultural lighting-present and future challenges. Lighting Res. Technol. 2012, 44, 427-437. [CrossRef]

26. Higgins, C. Current Status of Commercial Vertical Farms with LED Lighting Market in North America. In LED Lighting for Urban Agriculture; Kozai, T., Fujiwara, K., Runkle, E.S., Eds.; Springer: Singapore, 2016; pp. 309-315. [CrossRef]

27. Siekierski, A. Annual LED and Lighting Industry Directory 2018. Available online: https://issuu.com/ lightingeu/docs/lighting.eu_spring_2018 (accessed on 15 April 2020).

28. Mukish, P.; Boulay, P.; Vallo, M. Status of the Solid-State Lighting Source Industry 2019; Market and Technology Report Sample; Yole Développement: Lyon, France, July 2019.

29. Campisi, D.; Gitto, S.; Morea, D. Light Emitting Diodes Technology in Public Light System of the Municipality of Rome: An Economic and Financial Analysis. Int. J. Energy Econ. Policy 2017, 7, 200-208.

30. Campisi, D.; Gitto, S.; Morea, D. Economic feasibility of energy efficiency improvements in street lighting systems in Rome. J. Clean. Prod. 2018, 175, 190-198. [CrossRef]

31. Hayashi, E.; Higgins, C. Global LED Lighting Players, Economic Analysis, and Market Creation for PFALs. In LED Lighting for Urban Agriculture; Kozai, T., Fujiwara, K., Runkle, E.S., Eds.; Springer: Singapore, 2016; pp. 317-345. [CrossRef]

32. Marondedze, C.; Liu, X.; Huang, S.; Wong, C.; Zhou, X.; Pan, X.; An, H.; Xu, N.; Tian, X.; Wong, A. Towards a tailored indoor horticulture: A functional genomics guided phenotypic approach. Hortic. Res. 2018, 5. [CrossRef]

33. LEDinside. OSRAM Steadily Occupies the First Supplier of Horticultural Lighting with Its Superior LED Chip and Packing Technology. Available online: https://www.ledinside.com/interview/2020/5/osram_interview_ horticulture_led (accessed on 17 April 2020).

34. Zissis, G.; Bertoldi, P. Status of LED-Lighting World Market in 2017; Technical Report by the Joint Research Centre; European Commission: Ispra, Italia, 2018.

35. Mukish, P.; Boulay, P.; Andrieu, O.; Thome, J.; Pons, A. Horticultural LED Lighting; Technology, Industry, and Market Trends Report Sample; Yole Développement: Lyon, France, November 2017.

36. Hayashi, E. Current status of commercial plant factories with LED lighting market in Asia, Europe, and other regions. In LED Lighting for Urban Agriculture; Kozai, T., Fujiwara, K., Runkle, E.S., Eds.; Springer: Singapore, 2016; pp. 295-308. [CrossRef]

37. Hammond, D.; Goodman, S.; Wadsworth, E.; Rynard, V.; Boudreau, C.; Hall, W. Evaluating the impacts of cannabis legalization: The International Cannabis Policy Study. Int. J. Drug Policy 2020, 77, 102698. [CrossRef] [PubMed]

38. Reese, S.; Horowitz, K.; Mann, M.; Remo, T. Research note: LED lighting-A global enterprise. Lighting Res. Technol. 2020, 1-7. [CrossRef]

39. Van den Broeck, G.; Maertens, M. Horticultural exports and food security in developing countries. Glob. Food Sec. 2016, 10, 11-20. [CrossRef]

40. Jiang, C.; Johkan, M.; Hohjo, M.; Tsukagoshi, S.; Ebihara, M.; Nakaminami, A.; Maruo, T. Photosynthesis, plant growth, and fruit production of single-truss tomato improves with supplemental lighting provided from underneath or within the inner canopy. Sci. Hortic. 2017, 222, 221-229. [CrossRef]

41. GE lighting. Online Catalogue of GE LED Grow Bulbs. Available online: https://www.gelighting.com/ledbulbs/grow-light-led (accessed on 25 April 2020). 
42. Blackcob. Online Catalogue of Blackcob Lamps. Available online: https://www.blackcob.cl/iluminacion (accessed on 26 April 2020).

43. Fluence by Osram. Online Catalogue of Fluence by Osram Lighting Solutions for Controlled Environment Commercial Crop Production. Available online: https://shop.fluence.science/ (accessed on 4 May 2020).

44. Valoya. Online Catalogue of Valoya Lamps. Available online: https://www.valoya.com/wp-content/uploads/ 2020/05/EN_Product-Brochure_2020.2.pdf (accessed on 4 May 2020).

45. Fluence by Osram. Online Catalogue of VYPR Series. Available online: https:/fluence.science/products/ vypr-series/ (accessed on 6 May 2020).

46. Paucek, I.; Pennisi, G.; Pistillo, A.; Appolloni, E.; Crepaldi, A.; Calegari, B.; Spinelli, F.; Cellini, A.; Gabarrell, X.; Orsini, F; et al. Supplementary LED Interlighting Improves Yield and Precocity of Greenhouse Tomatoes in the Mediterranean. Agronomy 2020, 10, 1002. [CrossRef]

47. Fluence by Osram. Online Catalogue of RAZR Series. Available online: https:/fluence.science/products/ razr-series (accessed on 7 May 2020).

48. Fluence by Osram. Online Catalogue of SPYDRx Plus. Available online: https://shop.fluence.science/store/ spydr-series/spydrx-plus/ (accessed on 7 May 2020).

49. Vipple. Online Catalogue of Vipple lamps. Available online: https://www.vipple.cn/products/ (accessed on 11 May 2020).

50. Horticulture Lighting Group. Online Catalogue of Quantum Boards. Available online: https: //horticulturelightinggroup.com/collections/quantum-boards (accessed on 12 May 2020).

51. American Bright. Online Catalogue of Flexible Horticulture LED Solution. Available online: https: //drive.google.com/file/d/1iH0myEiRWrqub3E6MlN65VjEioDDiXTu/view (accessed on 15 May 2020).

52. Genesis Scientific. Online Catalogue of LED Grow Light Interflex. Available online: https://gs-horti.com/ images/PDF/LED\%20Grow\%20light\%20INTERFLEX\%20series-gs-horti.com.pdf (accessed on 15 May 2020).

53. Heilux. Online Catalogue of Growfilm Lamps. Available online: https://heiluxllc.com/new-index (accessed on 15 May 2020).

54. Bever Innovations. Online Catalogue of Bever Innovations Lamps. Available online: https://horticulture. beverinnovations.com/en/products/ (accessed on 18 May 2020).

55. Parus. Online Catalogue of Plant Factory Systems. Available online: http://www.parus.co.kr/list.php?ca_id= 40 (accessed on 18 May 2020).

56. Goto, E. Measurement of Photonmetric and Radiometric Characteristics of LEDs for Plant Cultivation. In LED Lighting for Urban Agriculture; Kozai, T., Fujiwara, K., Runkle, E.S., Eds.; Springer: Singapore, 2016; pp. 395-402. [CrossRef]

57. Fluence by Osram. How to Compare Grow Lights. Available online: https:/fluence.science/science-articles/ how-to-compare-grow-lights/ (accessed on 26 May 2020).

58. Yano, A. Configuration, Function, and Operation of LED Lighting Systems. In LED Lighting for Urban Agriculture; Kozai, T., Fujiwara, K., Runkle, E.S., Eds.; Springer: Singapore, 2016; pp. 403-415. [CrossRef]

59. Fujiwara, K. Radiometric, Photometric and Photonmetric Quantities and Their Units. In LED Lighting for Urban Agriculture; Kozai, T., Fujiwara, K., Runkle, E.S., Eds.; Springer: Singapore, 2016; pp. 367-376. [CrossRef]

60. Piromalis, D.; Arvanitis, K.G.; Papageorgas, P.; Ferentinos, K.P. Smart Precision Lighting for Urban and Landscape Closed Controlled Horticultural Environments. In Urban Horticulture: Sustainability for the Future; Nandwani, D., Ed.; Springer: Singapore, 2018; pp. 107-140. [CrossRef]

61. Kusuma, P.; Pattison, P.M.; Bugbee, B. From physics to fixtures to food: Current and potential LED efficacy. Hortic. Res. 2020, 7, 56. [CrossRef]

62. Gago-Calderón, A.; Orejón-Sánchez, R.D.; Hermoso-Orzáez, M.J. DC Network Indoor and Outdoor LED Lighting. In Light-Emitting Diode-An Outlook on the Empirical Features and Its Recent Technological Advancements; Thirumalai, J., Ed.; IntechOpen: London, UK, 2018; pp. 15-35. [CrossRef]

63. Pattison, P.M.; Hansen, M.; Tsao, J.Y. LED lighting efficacy: Status and directions. C. R. Phys. 2018, 19, 134-145. [CrossRef]

64. Tiu, A.L.; Odulio, C.M. A Dimmable Open-Loop Resonant LED Driver for a Horticulture Grow Light. In Proceedings of the TENCON 2018-2018 IEEE Region 10 Conference, Jeju, Korea, 28-31 October 2018; pp. 2357-2361. [CrossRef] 
65. Piromalis, D.; Arvanitis, K.; Papageorgas, P.; Tseles, D.; Psomopoulos, C. LEDWIRE: A Versatile Networking Platform for Smart LED Lighting Applications using LIN-Bus and WSNs. Sens. Transducers 2016, 200, 50-59.

66. Littlefuse. Designing for LED Horticulture Applications with Proper Circuit Protection. Available online: https://www.littelfuse.com/ \{\}/media/electronics/application_notes/littelfuse_horticulture_application_ note.pdf.pdf (accessed on 5 June 2020).

67. Hinov, N.; Tsankov, P.; Ibrishimov, H. Innovative LED Lighting. In Proceedings of the 2019 International Conference on Creative Business for Smart and Sustainable Growth (CREBUS), Sandanski, Bulgaria, 18-21 March 2019. [CrossRef]

68. Wu, B.S.; Hitti, Y.; MacPherson, S.; Orsat, V.; Lefsrud, M.G. Comparison and perspective of conventional and LED lighting for photobiology and industry applications. Environ. Exp. Bot. 2020, 171, 103953. [CrossRef]

69. Gupta, D.S.; Agarwal, A. Artificial Lighting System for Plant Growth and Development: Chronological Advancement, Working Principles, and Comparative Assessment. In Light Emitting Diodes for Agriculture; Gupta, D.S., Ed.; Springer: Singapore, 2017; pp. 1-25. [CrossRef]

70. Fluence by Osram. Online catalogue of RAY Series. Available online: https://1gt3sd9flvb3kwgha3wmyhbuwpengine.netdna-ssl.com/wp-content/uploads/2019/12/FLU-SpecSheet_RAY_WEB_2019-12.pdf (accessed on 15 June 2020).

71. Smart Grow Systems. Online Catalogue of Goldeni 500. Available online: https://smartgrow.systems/wpcontent/uploads/2018/12/GOLDENi-500-VERTICAL-FRAMEZ.pdf (accessed on 15 June 2020).

72. National Electrical Manufacturers Association (NEMA). ANSI/IEC 60529-2004: Degrees of Protection Provided by Enclosures (IP Code). Available online: https://www.nema.org/docs/default-source/standardsdocument-library/ansi-iec-60529.pdf (accessed on 22 June 2020).

73. Lumigrow. IP Rating in Greenhouse Equipment. Available online: https://www.lumigrow.com/learningcenter/blogs/ip-rating-greenhouse-equipment/ (accessed on 24 June 2020).

74. Sanlight Gmbh. Online Catalogue of Sanlight Flex Series. Available online: https://www.sanlight.com/en/ luminaires/sanlight-flex-series/ (accessed on 25 June 2020).

75. Marcelis, L.F.M.; Buwalda, F.; Dieleman, J.A.; Dueck, T.A.; Elings, A.; de Gelder, A.; Hemming, H.; Kempkes, F.L.K.; Lil, T.; van Noort, F.; et al. Innovations in crop production: A matter of physiology and technology. Acta Hortic. 2014, 1037, 39-45. [CrossRef]

76. Radetsky, L.C. LED and HID Horticultural Luminaire Testing Report; Report by Lighting Research Center; Rensselaer Polytechnic Institute: Troy, MI, USA, 2018.

77. Tungsram. Online Catalogue of Tungsram Greenhouse Linear Toplight. Available online: https://agritech. tungsram.com/en/products/toplight/linear-single\# (accessed on 2 July 2020).

78. Hyperion Grow Lights. Online Catalogue of Hyperion ${ }^{\mathrm{TM}} 3 \mathrm{k}$ Top Light. Available online: http://www. hyperiongrowlights.com/products/hyperion3k/ (accessed on 2 July 2020).

79. GE Current. Online Catalogue of Arize Element Top Lighting LED Growing System. Available online: https://products.gecurrent.com/horticulture/arize-element (accessed on 2 July 2020).

80. Heliospectra. helioCORE ${ }^{\mathrm{TM}}$. Available online: https://www.heliospectra.com/led-grow-light-controlsoftware (accessed on 6 July 2020).

(C) 2020 by the authors. Licensee MDPI, Basel, Switzerland. This article is an open access article distributed under the terms and conditions of the Creative Commons Attribution (CC BY) license (http://creativecommons.org/licenses/by/4.0/). 